\title{
Autosomal recessive cerebellar ataxia- epilepsy-intellectual disability syndrome due to RUBCN deficiency
}

INSERM

\section{Source}

INSERM. (1999). Orphanet: an online rare disease and orphan drug data base. Autosomal recessive cerebellar ataxia-epilepsy-intellectual disability syndrome due to RUBCN deficiency. ORPHA:404499

Autosomal recessive cerebellar ataxia-epilepsy-intellectual disability syndrome due to RUBCN deficiency is an extremely rare, autosomal recessive, hereditary cerebellar ataxia disorder characterized by early onset of progressive, mild to moderate gait and limb ataxia, moderate to severe dysarthria, and nystagmus or saccadic pursuit, frequently associated with epilepsy, moderate intellectual disability, delayed speech acquisition, and hyporeflexia in the upper extremities. Hyperreflexia in the lower extremities may also be associated. 